\title{
Egg shell derived apatite cement for the treatment of angular periodontal defects: A preliminary clinical and radiographic assessment
}

\author{
R. Jayasree ${ }^{1}$, J. Velkumar ${ }^{2}$ and T. S. Sampath Kumar ${ }^{1 *}$ \\ ${ }^{1}$ Medical Materials Laboratory, Department of Metallurgical and Materials Engineering, Indian Institute of Technology Madras, Chennai 600036, India \\ ${ }^{2}$ Department of Periodontics, Ragas Dental College and Hospital, Chennai 600019, India
}

\begin{abstract}
Development of alloplastic grafts for the treatment of periodontal osseous defects are moving towards designing biomaterials with optimized ultrastructure and composition to trigger assured biological function upon implantation. As eggshells are composed of calcium carbonate (94\%) along with traces of biologically beneficial ions such as $\mathrm{Mg}^{2+}, \mathrm{Sr}^{2+}, \mathrm{SiO}^{2-}{ }_{4}$, F-and $\mathrm{Na}^{+}$etc., calcium phosphates derived from this natural source may mimic bone composition. Calcium phosphate cements (CPC) are considered better candidates for periodontal regeneration because they act both as a graft material and barrier membrane to promote guided bone regeneration and can also progressively resorb. Earlier, we have reported eggshell derived CPC (ECPC) for first time and shown to have superior physical and biological properties than the synthetically derived CPC due to the presence of trace ions in ECPC. In the current study, we have evaluated the clinical efficacy of ECPC in treating angular periodontal osseous defects. The reduction in probing pocket depth (PD), gain in clinical attachment level (CAL) and change in gingival position were measured in a series of 6 patients and radiographs were taken at baseline and at 6 months. Results showed relative increase in PD and CAL of $44.7 \pm$ $6.3 \%$ and $50.9 \pm 11.5 \%$ respectively after 6 months. Bone regeneration was identified in the radiograph through trabecular continuity in the angular defect site at the end of 6 months along with complete resorption of ECPC. The results confirm ECPC as potential biomaterial for treating angular periodontal defects.
\end{abstract}

\section{Introduction}

Diseases affecting the periodontium are one of the most prevalent disorders worldwide which leads to the loss of the periodontal support structure including the cementum, periodontal ligament, and alveolar bone [1]. Histological evidences obtained from various clinical studies suggest that bone grafting is the best clinically viable treatment for the regeneration of bone, cementum, and functionally oriented new periodontal ligament coronal to the base of a previous osseous defect [2]. The clinical assessment of bone grafting procedures for patients with periodontitis are probing depth reduction, clinical attachment gain, bone filling of the osseous defect and regeneration of new bone, cementum and periodontal ligament [3].

Synthetic osteoconductive materials or alloplasts such as hydroxyapatite (HA), tricalcium phosphate $(\beta-\mathrm{TCP})$ and biphasic calcium phosphates (BCP) are widely used for the treatment of periodontal osseous repair [4,5]. Silica based glassy compositions such as bioglass and glass ceramics are also used for their fast resorption and high bioactivity properties [6]. As alloplast are completely synthetic in origin, disadvantages of autograft or xenograft materials such as donor site morbidity, limitation in amount and risk of disease transmission can be avoided. However, alloplast are less preferred because of their differing pace of resorption [7]. Clinicians consider synthetic HA as a non-resorbable material while $\beta$-TCP granules resorb too rapidly so that it loses its space-making capacity to guide new bone formation. Later, a new class of alloplast material known as calcium phosphate cements (CPC), raised hopes in periodontal repair. These are aqueous based cements that get converted to HA in situ upon setting. CPCs are biocompatible, osteoconductive and resorbable [8]. CPCs can act both as a graft material and barrier membrane to promote guided bone regeneration in defect site which makes it a unique material for bone grafting by acting significantly better than HA ceramic granules and thus it could be considered as a 'barrier-graft' [9].

Inorganic content of human bone is made of calcium phosphates substituted with trace ions such as $\mathrm{Mg}^{2+}, \mathrm{Sr}^{2+}, \mathrm{SiO}_{4}^{2-}, \mathrm{F}^{-}$and $\mathrm{Na}^{+}$and these ions play an important role in the bone regeneration [10]. For example, $\mathrm{Sr}^{2+}$ encourages bone formation by a dual mode of action: a stimulatory role on bone-forming osteoblast cells and an inhibitory role on bone resorbing osteoclast cells [11]. Calcium phosphates doped with magnesium has shown enhanced cell attachment, proliferation and alkaline phosphatase production [12]. It has also been reported that calcium phosphate doped with two or more trace elements has shown better biologic performance such as accelerated mineralization and significantly higher bone formation [13]. Presence of various biologically relevant ions in an optimal composition has been reported in eggshell [14]. Eggshell waste has been value engineered to various products for biomaterial applications such as calcium carbonate, $\mathrm{HA}, \beta$ -TCP, BCP, tetracalcium phosphate (TTCP) etc. $[14,15]$. The eggshell derived HA, $\beta$-TCP and $\mathrm{BCP}$ has already been used as a bone graft in animal model studies and human clinical trials with promising results [16-18]. In our previous study we synthesized phase-pure TTCP from

Correspondence to: TS Sampath Kumar, Department of Metallurgical and Materials Engineering, Medical Materials Laboratory, Indian Institute of Technology Madras, Chennai 600036, India, Tel: +91 044 22574772; E-mail: tssk@iitm.ac.in

Key words: angular periodontal defects, egg shells, alloplast, calcium phosphate cements, hydroxyapatite

Received: August 17, 2017; Accepted: September 04, 2017; Published: September 07, 2017 
eggshell waste and egg shell derived CPC (ECPC) was fabricated successfully for the first time [14]. The substitution of biologically relevant ions in ECPC greatly improved the properties such as setting time, mechanical strength, in vitro cell behavior of the cement samples. However, to the best of the available literature, the CPCs derived from a natural source have not been studied for its clinical bone regeneration efficacy in-vivo. The current study aims to evaluate the ability of ECPC to regenerate angular periodontal osseous defect in a series of six patients. Soft-tissue parameters such as probing depth (PD), clinical attachment level (CAL) and gingival recession (GR) and intra-oral radiographs were assessed for a period of 6 months.

\section{Material and methods}

\section{Fabrication of ECPC cement}

The cement for treating the angular periodontal defect was fabricated as reported earlier [14]. Briefly, powder component of the ECPC consists of TTCP derived from egg shell waste and dicalcium phosphate anhydrous, $\mathrm{CaHPO}_{4}$ in equimolar ratio. The liquid component contains $1 \mathrm{M}$ disodium hydrogen phosphate $\left(\mathrm{Na}_{2} \mathrm{HPO}_{4}\right)$ and $15 \%$ citric acid. The liquid and powder was taken in the ratio of $0.5 \mathrm{ml} / \mathrm{g}$ in a glass slab and was mixed with a spatula to a paste like consistency. The paste was then packed to the defect site within the initial setting time of 6 mins.

\section{Sample selection}

Six subjects were assessed ( 4 male and 2 female) for duration of 6 months for clinico-radiographic parameters at baseline and at the end of 6 months. The inclusion criteria for sample selection were patients with age range between 25-55 years, having minimum one interproximal two or three wall infrabony defect with probing depth $\geq 5 \mathrm{~mm}$ and clinical attachment loss of $>6 \mathrm{~mm}$ from the cementoenamel junction. They were evaluated for radiographic evidence of angular bone loss. Patients who are medically compromised, allergic to materials and drugs, taking calcium supplements, pregnant, lactating and postmenopausal females, with parafunctional habits such as bruxism are excluded from the study.

Teeth with furcation involvement, non-vital or endodontically treated teeth, third molars, and sites with one-walled defects were excluded from the study.

\section{Surgical strategies and protocol}

Initially, non-surgical periodontal therapy which included oral hygiene instruction, plaque control monitoring and scaling and root planning (SRP) were provided to patients. Sub-gingival instrumentation which required several sessions was performed by a periodontist. All probing assessments were performed with the use of a calibrated manual periodontal probe $(0.48 \mathrm{~mm}$ tip diameter), to the nearest millimeter at both the buccal and lingual aspects of the interdental site. Figure 1 shows the surgical steps followed during the procedure. Immediately before the surgical procedure, the patients were asked to rinse the mouth with a $0.2 \%$ chlorhexidine solution for 90 seconds. The surgical site was locally anaesthetized using $2 \%$ xylocaine with adrenaline $(1: 2,00,000)$. Intrasulcular incisions were given around the teeth followed by elevation of buccal and lingual fullthickness flaps. Flaps were designed to allow thorough debridement of the defects. Granulation tissue existing in the defect site was carefully excised and the root surface scaled and planned. No bone recontouring was performed. Care was taken to retain the interdental papillary tissue to the maximum possible extent. This was followed by isolation and
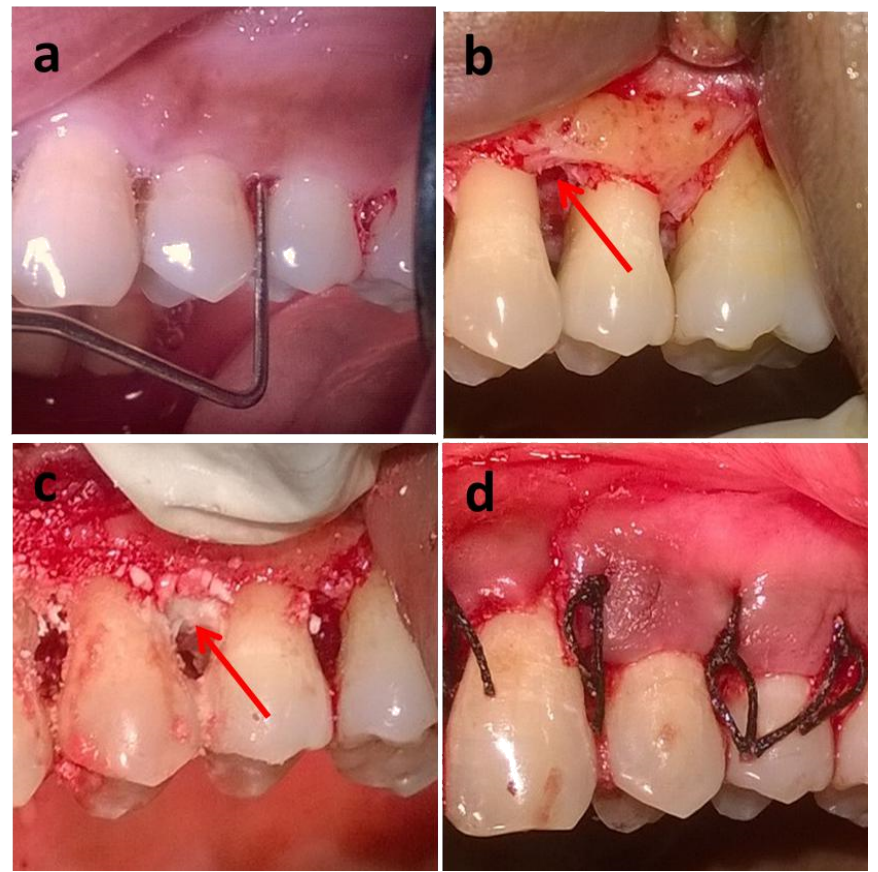

Figure 1. Grafting in the ECPC. (a) Defect site (b) shows the defect after flap elevation (red arrow shows the defect site) (c) defect site filled with ECPC (d) Defect closure with sutures.

drying of the areas. Consequently, the root surfaces were conditioned with topical application of tetracycline hydrochloride in distilled water $(100 \mathrm{mg} / \mathrm{ml})$ for 4 minutes using cotton pellets. The site was irrigated and dried again. ECPC prepared to a mouldable paste-like form was placed and packed in the osseous defects to the level of the respective crest (Figure 1c). On finishing the procedures, the flaps were replaced to their original level and sutured with silk by interrupted suturing (Figure 1d). Sufficient care was taken to achieve good primary closure over the grafted sites. Noneugenol periodontal dressings were given for 1 week. Antibiotics (doxycycline, $100 \mathrm{mg}$ BID for the first day followed by $100 \mathrm{mg}$ OD for 5 days), anti-inflammatory analgesic (ibuprofen $400 \mathrm{mg}$ TID for 3 days) and $0.2 \%$ chlorhexidine mouth wash were prescribed postoperatively. Patients were asked to report immediately if any untoward reaction (such as tooth pain or tissue inflammation) developed. The periodontal dressing and sutures were removed after one week. Oral hygiene instructions were reinforced and gentle supragingival cleaning was carried out. The patients were given review appointments at 6 months post-surgically for the data collection. Clinical attachment level (CAL), probing depth (PD) and gingival recession (GR) was measured.

\section{Statistical analysis}

Statistical comparisons of PD, CAL and GR within sites (Baseline vs post-treatment) were done using paired student $t$-test where $\mathrm{p}<0.05$ is considered significant.

\section{Results}

Data collected from individual cases are summarized in Table 1. The mean PD and CAL before and after 6-months treatment were summarized in Tables 2 and 3 respectively. The PD at baseline was 7.88 $\pm 1.414 \mathrm{~mm}$. The CAL at baseline was $8.5 \pm 1.14 \mathrm{~mm}$. After 6 months, the sites treated with ECPC exhibited a residual PD of $3.5 \pm 0.547$ $\mathrm{mm}$ and CAL of $4.33 \pm 0.836$. There was a statistically significant ( $\mathrm{p}$ $<0.001)$ reduction in both PD and CAL after 6-months of follow-up. 
Table 1. Summary of patient data.

\begin{tabular}{|c|c|c|c|c|c|c|c|c|}
\hline \multirow[b]{2}{*}{ Patient } & \multirow[b]{2}{*}{ Age } & \multirow[b]{2}{*}{ Sex } & \multirow[b]{2}{*}{ Tooth surface } & \multirow{2}{*}{$\begin{array}{l}\text { Type of defect } \\
\text { (walls) }\end{array}$} & \multicolumn{2}{|c|}{ Before treatment } & \multicolumn{2}{|c|}{ After 6 months } \\
\hline & & & & & $\begin{array}{l}\text { CAL } \\
(\mathrm{mm})\end{array}$ & $\begin{array}{c}\text { PD } \\
(\mathbf{m m})\end{array}$ & $\begin{array}{l}\text { CAL } \\
(\mathbf{m m})\end{array}$ & $\begin{array}{c}\text { PD } \\
(\mathbf{m m})\end{array}$ \\
\hline 1 & 43 & M & $16 \mathrm{D}^{*}$ & 3 & 9.0 & 9.0 & 5.0 & 4.0 \\
\hline 2 & 37 & M & $24 \mathrm{D}$ & 2 & 8.0 & 7.0 & 4.0 & 3.0 \\
\hline 3 & 42 & $\mathrm{~F}$ & $37 \mathrm{M}^{\$}$ & 2 & 10.0 & 10.0 & 5.0 & 5.0 \\
\hline 4 & 35 & $\mathrm{~F}$ & $26 \mathrm{D}$ & 3 & 8.0 & 7.0 & 4.0 & 3.0 \\
\hline 5 & 47 & M & $46 \mathrm{D}$ & 2 & 7.0 & 7.0 & 3.0 & 3.0 \\
\hline 6 & 51 & M & $14 \mathrm{M}$ & 2 & 9.0 & 7.0 & 5.0 & 4.0 \\
\hline
\end{tabular}

${ }^{*}$ Distal, ${ }^{\$}$ Mesial

Table 2. Changes in the probing depth during 6-month observation interval.

\begin{tabular}{|c|c|c|}
\hline \multirow{2}{*}{ Period } & \multicolumn{2}{|c|}{ PD $(\mathbf{m m})$} \\
\cline { 2 - 3 } & Mean & SD \\
\hline Baseline & $7.88^{*}$ & 1.414 \\
\hline 6 months & $3.5 *$ & 0.547 \\
\hline \% change & 44.7 & 6.3 \\
\hline Statistical significance & $* \mathrm{p}<0.001$ Highly significant \\
\hline
\end{tabular}

Table 3. Changes in the clinical attachment level during 6-month observation interval.

\begin{tabular}{|c|c|c|}
\hline \multirow{2}{*}{ Period } & \multicolumn{2}{|c|}{ CAL $(\mathbf{m m})$} \\
\cline { 2 - 3 } & Mean & SD \\
\hline Baseline & $8.5^{*}$ & 1.140 \\
\hline 6 months & $4.33^{*}$ & 0.836 \\
\hline \% change & 50.9 & 11.5 \\
\hline Statistical significance & $* \mathrm{p}<0.001$ Highly significant \\
\hline
\end{tabular}

Table 4. Changes in the gingival recession during 6-month observation interval.

\begin{tabular}{|c|c|c|}
\hline \multirow{2}{*}{ Period } & Mean & GR (mm) \\
\cline { 2 - 3 } & $0.66^{*}$ & 0.547 \\
\hline Baseline & $0.83^{*}$ & 0.288 \\
\hline $\begin{array}{c}\text { 6 months } \\
\text { Change in gingival } \\
\text { recession }\end{array}$ & 0.17 & 0.25 \\
\hline Statistical significance & \multicolumn{2}{|c|}{$* \mathrm{p}>0.5$ Not significant } \\
\hline
\end{tabular}

These clinical improvements represent relative increase in PD and CAL of $44.7 \pm 6.3$ and $50.9 \pm 11.5 \%$ respectively. Changes in the gingival recession during 6-month observation interval are shown in Table 4. No significant variation in gingival recession was observed before and after treatment $(\mathrm{p}>0.5)$.

Figure 2a shows the angular defect in relation to $16 \mathrm{D}$. Immediately after surgical procedure, post-operative radiograph was taken (Figure 2b) which shows the grafted ECPC material slightly radiopaque than the surrounding interdental bone. The radiographs taken after the $6^{\text {th }}$ month follow-up visits did not show any signs of resorption of root or bone in any of the cases, when compared with the preoperative radiographs. Figure $2 \mathrm{C}$ shows the new bone formation in relation to $16 \mathrm{D}$. Bone regeneration could be identified through trabecular continuity, progressively after 6 months in the postoperative period.

\section{Discussion}

Guided bone regeneration in periodontal regenerative therapies can be achieved by two techniques, namely 1) with grafts and 2) with barrier materials [19]. The combination technique of grafting along with barrier material called as a "barrier-graft" for guided tissue regeneration (GTR) infers that such material can significantly improve the clinical outcomes. However, due to the difficultly in surgical procedures and higher failure rates, the combination technique did

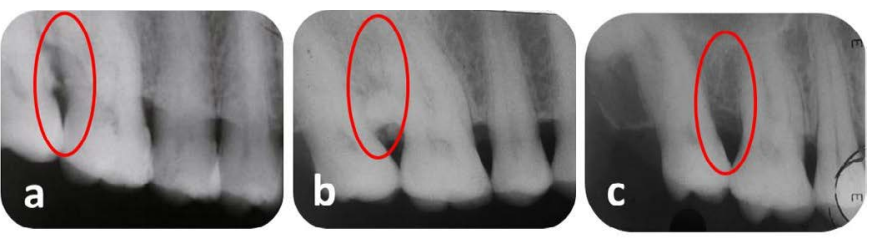

Figure 2. Intraoral radiographs of a selected case treated with ECPC in the defect site (16D) (a) Pre-operative, (b) after graft placement (c) after 6 months follow-up.

not gain recognition among clinicians [9]. The benefits of CPCs seem to fit to the barrier-graft concept because of its cementing property. Being a mouldable cement, it conformally fills the defect by excluding connective tissue and functional epithelium from the healing defect site, thereby satisfying the criterion for a GTR barrier [20]. Another distinguished feature of CPC is osteotransductivity. It can be described as resorption of the cement graft in tune with new bone formation [9]. These properties such as barrier-graft and osteotransductivity make CPC's ideal material for periodontal therapy with more predictable and better outcome.

The popular calcium sulphate bone cementing materials undergoes passive resorption in contact with body fluids before the formation of new bone at the defect site [21,22]. In contrast, sintered HA granules are too stable in body fluids or resorb very slowly because of their stoichiometric polycrystalline structure [8]. Our previous study confirms that ECPC consists of nanosized interlocked crystals of HA with weak interparticle boundaries [14]. Although HA is stable in body fluid the trace elements present in the ECPC could trigger the biologically mediated resorption of the HA crystals by osteoclast and macrophages. HA formed in the ECPC graft material also possesses non-stoichiometric destabilized crystal structure due to the presence of trace ions enabling faster degradation. While the resorption progresses, the osteoblast cells proceed with laying new bone in the space between host bone and the graft material. This process will continue till the whole material is resorbed and the defect is repaired completely. The 6 months results from this case series exhibit encouraging clinical outcome using ECPC graft material in angular osseous defects. The results demonstrated reduction in $\mathrm{PD}$ and gain in CAL of $4.33 \pm 0.867$ and $4.17 \pm 0.304$ respectively. Whereas, a study with CPC reports a pocket depth reductiosn and the mean clinical attachment level gain at 6 months as $3.30 \pm 1.17 \mathrm{~mm}$ and $1.95 \pm 1.70 \mathrm{~mm}$ respectively [23] Thus, the present study indicates that treatment of periodontal defects with ECPC is clinically superior when compared to traditional CPC which should be attributed to the presence of biologically relavant trace ions. Although this case series displays favourable results, long term studies may be further confirm the gain in $\mathrm{CAL}$ and $\mathrm{PD}$ reduction. 


\section{Conclusion}

This clinical case series demonstrate the regenerative approach of angular bone defects using eggshell derived CPC successfully. The 6-month results demonstrated favourable clinical outcome with relative improvement in $\mathrm{PD}$ and CAL of 44 and $50 \%$ respectively. Complete resorption of the material is evident from the radiographic results with new bone formation. Given the advanced and challenging nature of the osseous lesions, these improvements represent clinically significant outcomes.

\section{Conflicts of interest}

The authors declare that they have no conflicts of interests.

\section{References}

1. Nanci A, Bosshardt DD (2006) Structure of periodontal tissues in health and disease. Periodontol 2000 40: 11-28. [Crossref]

2. Rosenberg E, Rose LF (1998) Biologic and clinical considerations for autografts and allografts in periodontal regeneration therapy. Dent Clin North Am 42: 467-490. [Crossref]

3. Schallhorn RG, Hiatt WH, Boyce W (1970) Iliac transplants in periodontal therapy. $J$ Periodontol 41: 566-580. [Crossref]

4. Reynolds MA, Aichelmann-Reidy ME, Branch-Mays GL, Gunsolley JC (2003) The efficacy of bone replacement grafts in the treatment of periodontal osseous defects. A systematic review. Ann Periodontol 8: 227-265. [Crossref]

5. Rosen PS, Reynolds MA, Bowers GM (2000) The treatment of intrabony defects with bone grafts. Periodontol 2000 22: 88-103. [Crossref]

6. Fu Q, Rahaman MN, Fu H, Liu X (2010) Bioactive glass scaffolds with controllable degradation rates for bone tissue engineering applications. I. Preparation and in vitro degradation. J Biomed Mater Res 95A: 164-171.

7. Darby I (2011) Periodontal materials. Aust Dent J 1: 107-118. [Crossref]

8. Bohner M (2000) Calcium orthophosphates in medicine: from ceramics to calcium phosphate cements. Injury 4: 37-47. [Crossref]

9. Rajesh JB, Nandakumar K, Varma HK, Komath M (2009) Calcium phosphate cement as a "barrier-graft" for the treatment of human periodontal intraosseous defects. Indian $J$ Dent Res 20: 471-479. [Crossref]
10. Cacciotti I (2016) Cationic and Anionic substitutions in hydroxyapatite, In: Handbook of Bioceramics and Biocomposites, Iulian Vasile Antoniac Editor, Springer International Publishing: 145-211.

11. Marie PJ (2006) Strontium ranelate: a dual mode of action rebalancing bone turnover in favour of bone formation. Curr Opin Rheumatol 1: S11-15. [Crossref]

12. Xue W, Dahlquist K, Banerjee A, Bandyopadhyay A, Bose S (2008) Synthesis and characterization of tricalcium phosphate with $\mathrm{Zn}$ and Mg based dopants. J Mater Sci Mater Med 19: 2669-2677. [Crossref]

13. Bose S, Fielding G, Tarafder S, Bandyopadhyay A (2013) Understanding of dopantinduced osteogenesis and angiogenesis in calcium phosphate ceramics. Trends Biotechnol 31: 594-605. [Crossref]

14. Jayasree R, Sampath Kumar TS, Pavani Siva Kavya K, Rakesh Nankar P, Mukesh D (2015) Self setting bone cement formulations based on egg shell derived tetracalcium phosphate bioceramics. Bioceram Dev Appl 5: 084.

15. Sampath Kumar TS (2016) Value added bioceramics: A review of the developments and progress in India. Key Eng Mater 696: 3-8.

16. Kim SH, Kim W, Cho JH, Oh NS, Lee MH, et al. (2008) Comparison of bone formation in rabbits using hydroxyapatite and $B$ - tricalcium phosphate scaffolds fabricated from egg shells. Adv Mat Res 47-50: 999-1002.

17. Kattimani VS, Chakravarthi PS, Kanumuru NR, Subbarao VV, Sidharthan A, et al. (2014) Eggshell derived hydroxyapatite as bone graft substitute in the healing of maxillary cystic bone defects: A preliminary report. J Int Oral Health 6: 15-19. [Crossref]

18. Kattimani VS, Krishna Prasad L, Chakravarthi P, Managutti A, Katwala H, et al. (2016) Egg shell derived hydroxyapatite as bone graft material in maxillofacial skeleton A randomized blind multi-center clinical trial. Front. Bioeng Biotechnol. Conference Abstract: 10th World Biomaterials Congress.

19. Liu J, Kerns DG1 (2014) Mechanisms of guided bone regeneration: a review. Open Dent J 8: 56-65. [Crossref]

20. Hayashi C, Kinoshita A, Oda S, Mizutani K, Shirakata Y, Ishikawa I (2006) Injectable calcium phosphate bone cement provides favorable space and a scaffold for periodontal regeneration in dogs. J Periodontol 77: 940-946. [Crossref]

21. Maragos P, Bissada NF, Wang R, Cole BP (2002) Comparison of three methods using calcium sulfate as a graft/barrier material for the treatment of Class II mandibular molar furcation defects. Int J Periodontics Restorative Dent 22: 493-501. [Crossref]

22. Sottosanti J (1992) Calcium sulfate: A biodegradable and biocompatible barrier for guided tissue regeneration. Compendium 13: 226- 228, 230, 232-234. [Crossref]

23. Setoguchi T, Izumi Y, Oda S, Ishikawa I, Ryder MI, Veber Y (2005) Injectable calciumphosphate bone cement for periodontal bone defect. IADR/ AADR/CADR $83 \mathrm{rd}$ General Session, Baltimore.

Copyright: (C2017 Jayasree R. This is an open-access article distributed under the terms of the Creative Commons Attribution License, which permits unrestricted use, distribution, and reproduction in any medium, provided the original author and source are credited. 